\title{
PROJETOS DE MDL DE ENERGIA EÓLICA NO NORDESTE DO BRASIL: PERFIL E COBENEFÍCIOS DECLARADOS
}

\author{
Maria de Fátima Barbosa Góes \\ Doutoranda em Engenharia Industrial \\ Universidade do Estado da Bahia - UNEB \\ Salvador - Bahia - Brasil \\ mfbgoes@gmail.com \\ José Célio Silveira Andrade \\ Doutor em Administração \\ Universidade Federal da Bahia - UFBA \\ Salvador - Bahia - Brasil \\ jcelio.andrade@gmail.com \\ Marcelo Santana Silva \\ Doutor em Energia e Ambiente \\ Instituto Federal da Bahia - IFBA \\ Santo Amaro - Bahia - Brasil \\ profmarceloifba@gmail.com \\ Augusta Coelho Santana \\ Mestre em Administração \\ Faculdade Metropolitana de Camaçari - FAMEC \\ Camaçari - Bahia - Brasil \\ augustagcoelho@hotmail.com
}

\section{RESUMO}

Os projetos do Mecanismo de Desenvolvimento Limpo (MDL) devem ter como objetivo complementar a promoção de cobenefícios ambientais, sociais e econômicos para o desenvolvimento sustentável. Assim, o objetivo desta pesquisa é analisar o perfil e os cobenefícios declarados nos projetos de MDL de energia eólica no Nordeste do Brasil. Para isso, foi realizada uma análise documental de 47 Documentos de Concepção do Projeto (DCP) de todos os projetos de energia eólica no Nordeste, registrados pelo Conselho Executivo do MDL até maio de 2016. Os resultados mostram uma predominância de projetos de pequeno porte, localizados em distritos ou pequenos municípios, em especial no estado do Rio Grande do Norte (43\%). Mais de um terço dos projetos, apresenta estimativa de redução anual média de Gases do Efeito Estufa (GEE) de até 50.000 toneladas de $\mathrm{CO}_{2}$ equivalente. Em relação aos cobenefícios declarados, constatou-se que os cobenefícios ambientais são muito inferiores aos sociais e econômicos. O cobenefício ambiental mais citado foi a melhoria na qualidade do ar; o social mais citado foi a geração de novas oportunidades de emprego; e o econômico, o estímulo à economia regional. A análise concluiu que foi dada pouca ênfase à declaração dos cobenefícios nos DCP e que estes poderiam ser ampliados caso houvesse, no MDL, a previsão de mensuração e verificação dos cobenefícios gerados após a implantação do projeto, analogamente ao que já acontece com a redução das emissões de GEE.

Palavras-chave: Brasil. Cobenefícios para o desenvolvimento sustentável. Energia eólica; Projetos de MDL.

\section{WIND POWER CDM PROJECTS IN NORTHEAST BRAZIL: PROFILE AND DECLARED CO-} BENEFITS

\begin{abstract}
CDM (Clean Development Mechanism) projects should have as a secondary objective the promotion of environmental, social and economic co-benefits for sustainable development. Thus, the purpose of this research is to analyze the profile and declared co-benefits in CDM wind energy projects in Northeast of Brazil. Thus, a documentary analysis of 47 Project Design Documents (PDD) of all wind energy projects in the Northeast recorded by the CDM Executive Board until May 2016 was carried out. Results show a predominance of small projects, located in districts or small municipalities, especially in the state of Rio Grande do Norte $(43 \%)$. More than a third of the projects present an estimate of average annual reduction of Greenhouse Gases (GHG) of up to 50,000 tons of $\mathrm{CO}_{2}$ equivalent. With regard to declared co-benefits, we found that environmental co-benefits are much lower than the social and economic ones. The most cited environmental co-benefit was the improvement in air quality; the social most cited was the generation of new job opportunities; and the stimulus to regional economy. The analysis concludes that little emphasis was placed on declaration of the co-benefits in the PDD and that these could be expanded if there were in the CDM the prediction of measurement and verification of the co-benefits generated after the project implementation, similarly to what already happens with GHG emissions reduction.
\end{abstract}

Key words: Brazil; Co-benefits for sustainable development; CDM projects; Wind power. 


\section{INTRODUÇÃO}

O Mecanismo de Desenvolvimento Limpo (MDL) foi concebido durante as negociações do Protocolo de Kyoto, para auxiliar na estratégia de mitigação das mudanças climáticas e na promoção do desenvolvimento sustentável. Assim, por meio da comercialização dos créditos de carbono gerados pelos projetos de MDL, ao ser comprovada a redução das emissões dos Gases do Efeito Estufa (GEE), este instrumento ajuda os países desenvolvidos a atingirem suas metas de redução de emissões estabelecidas tendo como base o Protocolo. Ao mesmo tempo, os projetos devem ter o objetivo complementar de contribuir para que os países em desenvolvimento tornem-se mais sustentáveis (Unfccc, 2012; Watts, Albornoz \& Watson, 2015).

O sucesso na redução das emissões de GEE e no combate às mudanças climáticas depende, em grande medida, da transição da matriz energética mundial para um modelo mais sustentável, baseado em energias renováveis. Assim, apesar da matriz energética global ainda ser fortemente alicerçada em combustíveis fósseis não renováveis, o uso de fontes de energia de baixo carbono está se expandindo rapidamente, de tal forma que as energias renováveis representaram quase metade de toda a nova capacidade de geração de energia em 2014 (IEA, 2015).

Neste contexto é que vem sendo feitos investimentos crescentes no setor de energia eólica nos últimos anos no Brasil. Apesar de o Brasil ocupar a terceira posição na geração hidráulica em 2014, com a grave crise hídrica que o país vem enfrentando, a disponibilidade de energia hidrelétrica está diminuindo. Por outro lado, o potencial brasileiro de geração de energia eólica é bastante grande, com destaque para a Região Nordeste. Ao final de 2014, o Brasil ocupava o $3^{\circ}$ lugar no ranking de expansão de geração eólica. Esta expansão fez com que o país passasse da $15^{\mathrm{a}}$ posição no ranking mundial de geração de energia eólica em 2013 para a $10^{\mathrm{a}}$ posição em 2014 (MME, 2015).

Já no final de 2016, o Brasil possuía 430 parques eólicos, com capacidade instalada de 10,75 Gigawatts - o que equivale a uma média de 25 Megawatts por parque e representa um aumento de $23,06 \%$ de potência em relação a dezembro de 2015. Quanto às emissões de GEE, a redução relativa estimada foi de 17,81 milhões de toneladas de $\mathrm{CO}_{2}$ equivalente $\left(\mathrm{tCO}_{2} \mathrm{e}\right)$ naquele ano, sendo a média por parque de 41.418,60 $\mathrm{tCO}_{2} \mathrm{e}$. Dentre os 11 estados brasileiros que produziram energia eólica durante o ano de 2016, destacam-se os estados nordestinos do Rio Grande do Norte, com 10,59 Terawatt-hora (TWh), Bahia (6,08 TWh) e Ceará $(5,87 \mathrm{TWh})$, sendo sete estados nordestinos responsáveis por $87,14 \%$ da energia eólica gerada no país em dezembro de 2016 (ABEEólica, 2016a).

Os cobenefícios para o desenvolvimento sustentável dos projetos de MDL podem ser definidos como benefícios complementares ao objetivo principal de redução das emissões de GEE que estes projetos podem trazer para os países em desenvolvimento, dentro das três dimensões clássicas da sustentabilidade: econômica, ambiental e social (Unfccc, 2012). Como estes cobenefícios são subjetivos, a Unfccc buscou melhorar sua mensuração e publicização, criando uma ferramenta que permite aos proponentes dos projetos avaliarem voluntariamente os cobenefícios gerados utilizando critérios detalhados. As informações assim coletadas são usadas para criar um relatório que é publicado no site da Unfccc. Existem ainda poucos relatórios publicados, com predominância de projetos chineses e indianos, porém ainda não foi publicado nenhum relatório de cobenefícios dos projetos de MDL brasileiros (Unfccc, 2017).

Este trabalho é um work in progress, fazendo parte de um projeto de pesquisa maior patrocinado pelo Conselho Nacional de Desenvolvimento Científico e Tecnológico (CNPq), denominado "Análise dos cobenefícios dos projetos de redução de emissão de gases do efeito estufa no Brasil". Nessa pesquisa, foram realizados 20 estudos de caso de projetos de redução de GEE, principalmente de geração de energia eólica e aproveitamento de biogás em aterros sanitários. $\mathrm{O}$ destaque para o setor de energia eólica na pesquisa citada se deu em razão dos investimentos que vem sendo realizados recentemente no Nordeste e no Brasil. E pelo mesmo motivo, este setor foi 
selecionado como objeto de estudo da pesquisa de doutorado da autora principal deste artigo, a qual está em andamento.

Considerando o papel das energias renováveis em relação ao cenário atual e às perspectivas futuras da sustentabilidade e a inexistência de relatórios de cobenefícios de projetos de MDL brasileiros no site da Unfccc, percebe-se a importância de contribuir para preencher esta lacuna referente ao conhecimento sobre os cobenefícios dos projetos brasileiros de MDL de energia eólica. Acredita-se que esse conhecimento pode contribuir para a melhoria das políticas públicas nacionais e locais de fomento ao setor eólico e para o aumento dos cobenefícios gerados.

Várias pesquisas já realizadas enfocando os cobenefícios dos projetos de MDL no mundo, em países diversos e no Brasil, vem constatando uma contribuição para o desenvolvimento sustentável de pequena monta, especialmente no que tange aos cobenefícios sociais e ambientais (Fernández et al., 2012; McDowall et al., 2013; Fernández, 2014; Paiva, 2015; Paiva et al., 2015; Xue et al., 2015; Larragán, 2016; Murata et al., 2016; Olsen, Arens \& Mersmann, 2017; Lazaro \& Gremaud, 2017).

Assim, com este trabalho, pretendeu-se responder à seguinte pergunta de pesquisa: "Como são o perfil e os cobenefícios para o desenvolvimento sustentável declarados nos projetos de MDL de energia eólica no Nordeste do Brasil?". O objetivo da pesquisa é realizar uma análise do perfil e dos cobenefícios declarados nos projetos de MDL de energia eólica localizados nesta região. Para isto, foi utilizada a técnica de pesquisa documental para analisar 47 Documentos de Concepção do Projeto (DCP ou PDD, do inglês Project Design Document) de todos os projetos eólicos na região que possuíam o status de "registrado" pelo Conselho Executivo do MDL em maio de 2016.

O artigo encontra-se estruturado da seguinte forma: após esta introdução, é apresentada a revisão da literatura, que inclui os conceitos de mercado de carbono, projetos de MDL, e, mais especificamente, os de energia eólica, e seus cobenefícios; em seguida, são apresentados os procedimentos metodológicos, incluindo os modelos de análise utilizados; depois são apresentados e discutidos os resultados obtidos; e por último são evidenciadas as considerações finais do trabalho.

\section{REVISÃO DA LITERATURA}

A revisão de literatura realizada focou os conceitos de: mercado de carbono; projetos de MDL em geral, e do setor de energia eólica em particular; e seus cobenefícios para o desenvolvimento sustentável, que se referem a benefícios não associados diretamente à redução das emissões de GEE, necessariamente gerada por estes projetos.

\subsection{Mercado de carbono e projetos de MDL}

Em 1988, o Programa das Nações Unidas para o Meio Ambiente (Pnuma ou Unep, do inglês United Nations Environment Programme) e a Organização Meteorológica Mundial (OMM ou WMO, do inglês World Meteorological Organization) criaram o Painel Intergovernamental sobre Mudança do Clima (Pimc, mais conhecido como Ipcc, do inglês Intergovernmental Panel on Climate Change). Com a criação do Ipcc, composto por cientistas especializados de todo o mundo, consolidou-se a aceitação, por parte da Organização das Nações Unidas (ONU), da existência do fenômeno do aquecimento global. Isso porque o Ipcc vem publicando relatórios contundentes sobre o impacto da interferência antrópica no clima. Em resposta às constatações do Ipcc, uma abordagem política foi iniciada, em 1992, com a realização no Rio de Janeiro da Conferência das Nações Unidas sobre Meio Ambiente e Desenvolvimento, quando foi criada a Convenção Quadro das Nações Unidas sobre Mudanças Climáticas (Cqnumc ou Unfccc, do inglês United Nations Framework Convention on Climate Change), com o objetivo principal de conter e estabilizar as emissões de GEE para a atmosfera (Viola, 2005; Andrade \& Costa, 2008).

Fruto das discussões internacionais sobre o aquecimento global, em 1997 foi assinado o 
Protocolo de Kyoto, tendo como um dos objetivos a proteção do sistema climático para o benefício das gerações presentes e futuras. O Protocolo de Kyoto - que só entrou em vigor em 2005, após intenso debate político, e estabeleceu um primeiro período de compromissos obrigatórios de redução de emissões de GEE para os países desenvolvidos de 2008 a 2012 - não estabeleceu obrigações para os países em desenvolvimento. Porém, ao definir metas de redução dos níveis de emissão para os países desenvolvidos (signatários do Protocolo e listados no seu Anexo I), estabeleceu também mecanismos de flexibilização, que viabilizariam o atendimento dos compromissos firmados por estes países por meio da compensação de emissões. Dentre estes mecanismos, estão a Implementação Conjunta e o Comércio de Emissões, que tem atuação restrita entre países do Anexo I, e o Mecanismo de Desenvolvimento Limpo (MDL), proposta de iniciativa brasileira que permitiu o financiamento por países desenvolvidos de projetos de redução de emissões de GEE implantados em países em desenvolvimento (Brasil, s/d; Andrade \& Costa, 2008; Seiffert, 2009).

Para implementação do mecanismo de Comércio de Emissões, foi criado o Mercado Regulado de Carbono (MRC), cuja base são os projetos de MDL, os quais geram as Reduções Certificadas de Emissões (RCE), comumente denominadas de créditos de carbono. $\mathrm{O}$ mercado regulado de carbono é o ambiente institucional que define as regras para a concepção dos projetos e a comercialização dos créditos. É um mercado com potencial de crescimento em países em desenvolvimento, como o Brasil. Além de obter vantagens financeiras com a venda dos créditos, as empresas brasileiras podem aliar à sua imagem a responsabilidade socioambiental e as tecnologias mais limpas (Paiva et al., 2012; Paiva, 2015). Entretanto, o interesse em participar deste mercado tem diminuído em razão do baixo preço dos créditos de carbono, reflexo da crise econômica global e da incerteza em relação ao futuro da governança ambiental do clima, particularmente antes da assinatura do Acordo de Paris (Souza, Alvarez \& Andrade, 2013; Godoy \& Saes, 2015).

Os projetos de MDL podem envolver a substituição de energia de origem fóssil por outra de fonte renovável, a racionalização do uso da energia, serviços urbanos ou outras atividades que reduzam as emissões de GEE. A Unfccc adotou uma lista de 15 escopos setoriais para os projetos, com base no Anexo A do Protocolo, que lista todos os gases do efeito estufa e os setores/categorias de fontes emissoras desses gases. Entre estes setores, encontram-se desde a indústria de energia (tanto de fontes renováveis, quanto não-renováveis) até a agricultura, passando pelo transporte; tratamento e disposição de resíduos; reflorestamento; emissões fugitivas; e uso de solventes.

De acordo com relatório do Ministério da Ciência, Tecnologia e Inovação (Mcti), até 2014 havia 7.579 projetos de MDL registrados no mundo, sendo o primeiro lugar ocupado pela China, com 50\% dos projetos; o segundo, pela Índia, com 20\%; e o terceiro, pelo Brasil, com apenas 4\%, totalizando 330 projetos. A maior parte dos projetos brasileiros que estava ligada à indústria de energia, era de grande porte e localizava-se principalmente no centro-sul do país (Mcti, 2014).

No final de 2015, durante a $21^{\mathrm{a}}$ Conferência das Partes (COP 21) da Unfccc, foi aprovado o Acordo de Paris que possui metas de redução de emissões de GEE para todos os países desenvolvidos e em desenvolvimento - definidas nacionalmente conforme as prioridades e possibilidades de cada um. Segundo Larragán (2016), o Acordo de Paris prevê o estabelecimento futuro de regras, modalidades e procedimentos para novos mecanismos de mercado, os quais, provavelmente, deverão incorporar os aprendizados obtidos com a utilização dos mecanismos de flexibilização do Protocolo de Kyoto, inclusive o MDL. O novo mecanismo ainda não está definido, sendo as únicas condições impostas a promoção do desenvolvimento sustentável, a integridade ambiental e a proibição de dupla contagem da redução de emissões de GEE. Segundo o autor, a chave para a sua eficácia dependerá do estabelecimento de metas rigorosas de redução de emissões e de um sistema de governança que busque garantir a conformidade e o cumprimento destas metas.

Olsen, Arens \& Mersmann (2017) afirmam que o novo Mecanismo de Mitigação Sustentável (SMM, do inglês Sustainable Mitigation Mechanism), estabelecido pelo Artigo 6 do Acordo de Paris, apresenta um foco mais equilibrado entre a mitigação das mudanças climáticas e os objetivos do desenvolvimento sustentável. Assim, os cobenefícios para o desenvolvimento 
sustentável deverão ser avaliados da mesma forma que as reduções de emissões de GEE, implicando no monitoramento, na geração de relatórios, no estabelecimento de procedimentos para validação e verificação, por parte de atores independentes, dos cobenefícios declarados pelos proponentes dos projetos.

Por fim, cumpre destacar que - apesar de o conceito de desenvolvimento sustentável ser polissêmico, ou seja, possuir várias definições, que incluem diferentes dimensões da sustentabilidade - a abordagem dos cobenefícios para o desenvolvimento sustentável adotada neste trabalho segue o conceito clássico. Logo, as dimensões analisadas são a social, a ambiental e a econômica, utilizando como base o modelo "triple bottom line", bastante recorrente na literatura sobre desenvolvimento sustentável (Silva Jr. et al., 2011). Dessa forma, busca-se obter maior aderência ao Protocolo de Kyoto, marco regulatório no qual o MDL está inserido.

\subsection{Cobenefícios para o desenvolvimento sustentável de projetos de MDL}

Os cobenefícios dos projetos de MDL podem ser entendidos como ganhos - que vão além da redução das emissões de GEE - baseados no tripé da sustentabilidade: crescimento econômico aliado a justiça social e proteção ambiental (Unfccc, 2012; Fernández et al., 2014). Porém, ao contrário do que acontece com o objetivo principal do MDL - qual seja a redução das emissões de GEE, que é mensurada, validada, verificada e certificada -, no caso do objetivo complementar de contribuir para o desenvolvimento sustentável, embora seja um item obrigatório do DCP, não existe previsão de avaliação relativa ao seu alcance na prática, após a implementação do projeto (Fernández, 2014). Portanto, uma das principais críticas aos projetos de MDL, no que tange à promoção do desenvolvimento sustentável, diz respeito à inexistência de um instrumento oficial de medição e acompanhamento dos cobenefícios efetivamente gerados pelos projetos (Bogo, 2012; Fernández et al., 2012; Paiva et al., 2015; Olsen, Arens \& Mersmann, 2017).

Assim, como ainda não havia uma lista pactuada de indicadores adequados para mensuração dos cobenefícios dos projetos de MDL, a Unfccc (2012) estabeleceu um conjunto de dez indicadores, buscando mensurar a contribuição destes projetos para o desenvolvimento sustentável, considerando suas três dimensões. Assim, na dimensão econômica, os indicadores avaliam, por exemplo, a dinamização da economia local, incluindo a criação de emprego e redução da pobreza, e o desenvolvimento ou difusão da tecnologia; na ambiental, a redução da poluição, a preservação dos recursos naturais e a promoção de energia confiável e renovável; e na social, a melhoria das condições de saúde e segurança e o envolvimento da comunidade local, entre outros.

Em seguida, a Unfccc (2012) estudou os DCP de 3.864 projetos registrados e submetidos a registro até junho de 2012, tabulando os cobenefícios declarados com base nos indicadores de desenvolvimento sustentável estabelecidos. Este estudo concluiu que os cobenefícios mais frequentes eram a dinamização da economia local, incluindo a criação de emprego e redução da pobreza (29\%); a redução da poluição (22\%); e a promoção de energia confiável e renovável (19\%).

Larragán (2016) questiona o fato de os projetos de MDL não estarem enfocando as dimensões sociais e econômicas de forma geograficamente equilibrada em todo o mundo. Afirma que muitos projetos foram acusados de não contribuírem para o desenvolvimento sustentável e de se concentrarem em um pequeno número de grandes países em desenvolvimento. Apenas quatro países (Índia, China, Brasil e México) registraram, por vezes, até $85 \%$ de todos os projetos de MDL e nunca menos de $60 \%$, enquanto menos de $2 \%$ dos projetos são de países africanos.

Em um estudo visando avaliar a contribuição dos projetos de MDL para a sustentabilidade em três países latino-americanos - Brasil, México e Peru - Lazaro \& Gremaud (2017) verificaram que, no Brasil e no Peru, o setor de energia apresenta o maior número de projetos de MDL registrados, enquanto, no México, o setor de gestão e tratamento de resíduos é o que lidera. Estes autores concluíram que nem todos os projetos analisados contribuíram para o desenvolvimento sustentável. No Brasil e no Peru, a dimensão econômica foi a mais enfatizada, enquanto no México o foco maior foi na dimensão ambiental.

Revista de Gestão Social e Ambiental - RGSA, São Paulo, v. 12, n. 2, p. 71-89, maio/ago. 2018. 
Os critérios utilizados por estes autores para avaliar os cobenefícios dos projetos na dimensão econômica foram: a criação de empregos, a segurança energética, a criação de infraestrutura e a transferência de tecnologia. Assim, dos 461 projetos estudados, registrados no primeiro período do Protocolo de Kyoto, $51 \%$ dos DCP declararam contribuir para a segurança energética e $45 \%$ explicitaram como cobenefício a geração de empregos (Lazaro \& Gremaud, 2017).

Quanto aos cobenefícios dos projetos de MDL brasileiros, Bogo (2012) e Fernández et al. (2012) estudaram projetos no estado de Santa Catarina e concluíram que os mesmos contribuíram para o desenvolvimento sustentável local, sendo os maiores cobenefícios verificados pertencentes à dimensão econômica - benefícios financeiros diretos ou indiretos sobre a economia local, geração de emprego local direta ou indiretamente relacionada com o projeto ou melhorias na infraestrutura e nos serviços locais - e à dimensão ambiental - incluindo a segurança ambiental e a utilização eficiente, melhoria ou proteção de recursos naturais.

Paiva (2015) estudou projetos brasileiros de redução de GEE participantes do mercado voluntário de carbono e concluiu que a dimensão econômica dos cobenefícios se destacou em relação às outras dimensões, seguida pela dimensão ambiental, e por fim a social. Os cobenefícios mais verificados nesta pesquisa foram o desenvolvimento ou a difusão local da tecnologia e a dinamização da economia local, incluindo a criação de empregos e a redução da pobreza.

Fernández (2014), ao estudar em profundidade 20 projetos brasileiros de redução de GEE, concluiu que a maioria dos cobenefícios identificados - como a criação de empregos, a difusão da tecnologia ou a redução de odores em aterros sanitários - não era adicional, e que poderia ser verificada sem a implantação do projeto, devido a práticas como o licenciamento ambiental e a responsabilidade social empresarial (RSE). Observou também que os projetos pesquisados sofriam influência direta da sua natureza e dos atores proponentes. A autora verificou que os projetos industriais - entre os quais encontram-se a maioria dos projetos brasileiros - por si só não traziam mais cobenefícios que os solicitados nas suas atividades, e sugeriu que deveriam ser propostos mecanismos para que o proponente do projeto assumisse um compromisso com a geração de cobenefícios adicionais. Apontou, ainda, a importância de identificar quem são os beneficiários dos cobenefícios gerados e a necessidade de definir processos de consulta efetivos, de forma a envolvêlos. Por fim, esta autora conclui que apenas os requisitos da Unfccc não foram um estímulo considerável para a criação de cobenefícios nos locais onde os projetos de MDL foram implantados.

Considerando questões como as aqui expostas, Watts, Albornoz \& Watson (2015) sugerem melhorias no MDL, para que este cumpra seu papel de promoção do desenvolvimento sustentável. Algumas das medidas propostas incluem o estabelecimento de parâmetros uniformes para projetos semelhantes, a simplificação do processo de registro, e o fornecimento de ajuda internacional para os países menos desenvolvidos que historicamente não tiveram capacidade de participar do MDL.

\subsection{Cobenefícios dos projetos de MDL de energia eólica}

Existem alguns estudos que abordam os cobenefícios dos projetos de MDL de energia eólica, principalmente na China, país que detém a liderança em número de projetos de MDL no mundo. Murata et al. (2016) pesquisaram os cobenefícios ambientais dos projetos de MDL de energia renovável na China e na Índia, com foco em eólica, solar e biomassa. Os autores concluíram que os cobenefícios dos projetos de energia renovável dependem das políticas de padrão de emissões dos países anfitriões. Na China, a partir de julho de 2011, com a promulgação de um rigoroso padrão de emissões para usinas de energia, em relação ao controle das emissões de $\mathrm{SO}_{\mathrm{x}} \mathrm{e}$ $\mathrm{NO}_{\mathrm{x}}$ nas novas usinas termelétricas, a carvão está bastante avançado, afetando a linha de base dos projetos de MDL. Assim, neste país a redução de emissões encontra-se muito menor do que antes e o efeito dos cobenefícios ambientais dos projetos de MDL de energias renováveis tem se revelado bastante limitado. 
Já na Índia, a situação é bem diferente. O padrão de emissões para poluentes atmosféricos abrange apenas material particulado. Portanto, a tendência é que o controle das emissões de $\mathrm{SO}_{\mathrm{x}} \mathrm{e}$ $\mathrm{NO}_{x}$ seja inexistente ou, na melhor das hipóteses, pouco rigoroso. Então, os projetos de MDL de energia renovável tem maior potencial de reduzir as emissões destes poluentes, gerando cobenefícios ambientais mais efetivos (Murata et al., 2016).

Segundo Zhou, Li \& Huang (2015), o MDL pode ser uma ferramenta poderosa de acesso a tecnologias limpas, sendo uma forma inovadora para sustentabilidade, capaz de reduzir as emissões de GEE, além de propiciar cobenefícios. Os autores investigaram os projetos de MDL de energia eólica e solar na cidade de Shenzhen, localizada no sul da China, constatando algumas melhorias, tais como a tendência de transição de uma matriz energética dominada pelo carvão para outra dominada por energias mais limpas, que incluem a energia nuclear e a gerada pelo gás natural; a diversificação do mix de geração de energia da cidade pela utilização das fontes eólica e solar; o desenvolvimento local das energias renováveis motivado pelos projetos de MDL; e a contribuição para a redução de emissões da ordem de 71 a 85 milhões de toneladas de $\mathrm{CO}_{2}$ equivalente.

Xue et al. (2015) realizaram uma análise de ciclo de vida para o setor eólico usando os padrões de inventário da China. Estes autores compararam uma usina eólica com uma termelétrica a carvão, ambas com a mesma capacidade produtiva, e concluíram que a usina eólica apresentou uma redução nas emissões de $\mathrm{CO}_{2}$ de $97,48 \%$. Houve também reduções significativas nas emissões de outros poluentes atmosféricos $\left(\mathrm{SO}_{2}, \mathrm{NO}_{\mathrm{x}}\right.$ e $\left.\mathrm{PM}_{10}\right)$, as quais são consideradas cobenefícios ambientais. Os resultados dessa pesquisa destacam a necessidade de desenvolver a energia eólica para a geração de maiores benefícios ambientais.

O desenvolvimento da energia eólica na China, na Europa e nos Estados Unidos foi estudado por McDowall et al. (2013), com foco na evolução das políticas e do sistema de inovação. Os autores afirmam que a atuação política do governo central chinês e os compromissos assumidos visando criar uma indústria nacional geraram confiança por parte dos investidores para atuar naquele mercado. Citam a pesquisa de Lewis (2010) que avaliou a importância do financiamento de carbono no setor eólico chinês, verificando que a maioria do financiamento para energia eólica prove de corporações estatais. Assim, concluiu que o MDL não foi um grande estímulo à implantação de parques eólicos ou à transferência de conhecimento, a qual seria um cobenefício da dimensão econômica.

Por outro lado, Zhao, Li \& Xia (2014) afirmam exatamente o contrário: que o MDL tem sido uma das estratégias mais eficientes de desenvolvimento das energias renováveis, em especial a energia eólica. Com a implementação dos projetos de MDL, tem havido uma tendência de queda rápida do preço de custo da eletricidade gerada por fonte eólica, sendo os créditos de carbono recebidos o principal fator externo que influencia o preço de custo. Entretanto, dois fatores internos revelaram-se preponderantes: a produção anual e o investimento estático, que é relacionado ao custo dos aerogeradores.

No que se refere aos cobenefícios para o desenvolvimento sustentável de projetos de MDL de energia eólica brasileiros, ainda são poucos os trabalhos encontrados com este foco específico. Silva Jr. et al. (2011) pesquisaram as contribuições para a geração de tecnologias mais limpas e a promoção do desenvolvimento sustentável de dois projetos de MDL de energia eólica representativos da realidade brasileira naquele momento: Rosa dos Ventos e Água Doce. Seus achados indicaram que os projetos estudados utilizavam tecnologias mais limpas e contribuíam para o desenvolvimento sustentável de forma relativamente equilibrada entre as dimensões econômica, ambiental e social.

Simas e Pacca (2013) destacam os cobenefícios de criação de empregos - mais numerosos no curto prazo, durante a construção dos parques eólicos - e geração de renda, principalmente quando as comunidades na área de influência direta dos parques encontram-se em localidades rurais com poucas oportunidades econômicas. Estes autores defendem que a implantação de parques eólicos seja combinada com políticas eficientes de gestão de recursos e de desenvolvimento regional, de forma a aumentar sua contribuição para o desenvolvimento sustentável. 
No entanto, Silva et al. (2013) destacam a existência de conflitos sociais em algumas áreas de influência de parques eólicos no Nordeste, ligados à apropriação indevida de terras de uso coletivo e à postura dos governos locais. Os autores afirmam que, apesar de haver criação de empregos para a comunidade, pela característica de fragilidade socioeconômica destas áreas, os poucos postos ocupados são de baixa qualificação. Por fim, consideram que os esforços feitos para promoção da aceitação da energia eólica por parte da comunidade local, não vem sendo suficientes e que esta questão se revelará crítica para o desenvolvimento do setor nos próximos anos.

Pamplona \& Fraissat (2017) acreditam que os benefícios dos projetos de energia eólica implantados no Nordeste estão concentrados "nas mãos de poucos", e terminam por aumentar as desigualdades sociais, que já são grandes na região. Os autores afirmam que os maiores beneficiários são os proprietários de terras que arrendam uma pequena parte delas para a instalação dos aerogeradores, recebendo uma renda mensal entre $\mathrm{R} \$ 1.200,00$ e $\mathrm{R} \$ 1.800,00$ reais por cada aerogerador. Ainda, segundo os autores, a ABEEólica estima que, considerando todo o território nacional, mais de quatro mil famílias recebem cerca de dez milhões de reais por mês pelo arrendamento das suas terras.

\section{PROCEDIMENTOS METODOLÓGICOS}

A escolha do procedimento metodológico da pesquisa é uma etapa fundamental para dar robustez à análise dos dados coletados. Assim, esta pesquisa privilegia estratégias e técnicas de pesquisa qualitativa, tendo sido dado um tratamento quantitativo aos dados coletados, o qual serviu de apoio para a análise qualitativa. Como este trabalho deriva de um projeto de pesquisa maior sobre os cobenefícios de projetos de redução de GEE, os procedimentos metodológicos utilizados para elaboração deste artigo incluíram as duas primeiras fases das três cumpridas nessa pesquisa maior. Na primeira fase, foi realizada uma pesquisa empírica exploratória sobre projetos de MDL do setor eólico no Nordeste Brasileiro e a revisão da literatura especializada (nacional e estrangeira). Já na segunda, foi construído um modelo de análise da pesquisa, a partir do qual foi realizada a análise documental dos dados secundários coletados durante a pesquisa exploratória.

$\mathrm{Na}$ pesquisa documental realizada para este artigo, inicialmente foram consultados documentos em forma de planilhas Excel, que forneceram as informações necessárias para traçar o perfil dos parques eólicos. As principais fontes foram a ABEEólica (2016b) e a instituição internacional de pesquisa e consultoria sobre energia, clima e desenvolvimento sustentável formada por meio de uma parceria entre o Programa das Nações Unidas para o Meio Ambiente (Unep, na sigla em inglês) e a Universidade Técnica da Dinamarca (DTU, na sigla em inglês). Esta instituição publica informações atualizadas e abrangentes sobre os projetos de MDL, seus proponentes, e até mesmo sobre os compradores dos créditos de carbono no documento intitulado CDM Pipeline (Unep DTU Partnership, 2016).

Após consultas a estas bases de dados, foram extraídos do site da Unfccc todos os 47 documentos de concepção dos projetos de energia eólica da região do Nordeste Brasileiro que possuíam o status de "registrado" (pelo Conselho Executivo do MDL) em maio de 2016. Estes documentos foram a principal fonte de coleta dos dados secundários, em especial os referentes aos cobenefícios declarados na sua Seção "A.2. Description of the project activity".

Com base na revisão de literatura e do mapeamento dos DCP, foi feita a problematização do objeto de estudo, para a construção dos modelos de análise da pesquisa. Para alcançar o objetivo deste trabalho, foi necessário traçar o perfil dos parques eólicos localizados no Nordeste Brasileiro cadastrados como MDL, além de analisar os cobenefícios para o desenvolvimento sustentável declarados nos DCP. Assim, foram construídos dois modelos de análise, que detalham critérios e indicadores definidos de forma a caracterizar os parques e estimar seus cobenefícios. A Figura 1, a seguir, mostra o modelo utilizado para traçar o perfil dos parques, baseado prioritariamente nos dados disponíveis no CDM Pipeline, e secundariamente na planilha da ABEEólica e nos próprios documentos de concepção dos projetos. 


\begin{tabular}{|c|c|c|}
\hline \multirow{15}{*}{$\begin{array}{l}\text { Perfil dos parques eólicos } \\
\text { cadastrados como MDL no } \\
\text { Nordeste Brasileiro }\end{array}$} & Critérios & Indicadores \\
\hline & \multirow{2}{*}{ Identificação } & $\mathrm{N}^{\mathrm{o}}$ do $\mathrm{DCP}$ \\
\hline & & Título do projeto \\
\hline & \multirow{2}{*}{ Localização } & Estado da Federação \\
\hline & & Município / distrito \\
\hline & \multirow{3}{*}{ Histórico } & Data de submissão inicial à Unfccc \\
\hline & & Data do registro pela Unfccc \\
\hline & & Data inicial do $1^{\circ}$ período de crédito \\
\hline & \multirow{3}{*}{ Atores-chaves } & Investidor \\
\hline & & Consultor do DCP \\
\hline & & Fornecedor do aerogerador \\
\hline & \multirow{4}{*}{ Dados quantitativos } & Investimento (milhões de dólares) \\
\hline & & Potência (MW) \\
\hline & & Quantidade de aerogeradores \\
\hline & & Redução anual média estimada $\left(\mathrm{tCO}_{2} \mathrm{e}\right)$ \\
\hline
\end{tabular}

Figura 1 - Modelo de análise do perfil dos parques eólicos do Nordeste Brasileiro

Fonte: Elaborado pelos autores a partir de Unep DTU Partnership (2016), ABEEólica (2016b) e DCP.

Já o segundo modelo de análise, mostrado na Figura 2 a seguir, foi utilizado para sistematizar e estimar os cobenefícios declarados na seção A.2 dos DCP dos projetos de MDL estudados, citada anteriormente. A principal fundamentação deste modelo é a ferramenta aprovada na $70^{a}$ reunião do Conselho Executivo do MDL, no final de 2012, e disponibilizada posteriormente no site da Unfccc. Esta ferramenta consiste em um questionário amplo, dividido nas três dimensões da sustentabilidade, que fornece meios para os participantes dos projetos avaliarem voluntariamente os cobenefícios gerados utilizando critérios detalhados. Entretanto, além desta ferramenta, foram também utilizados como base para este modelo analítico os trabalhos de Fernández (2014) e Paiva (2015).

\begin{tabular}{|c|c|c|c|}
\hline Dimensões & Critérios / Indicadores & $\begin{array}{l}\text { Pontuação } \\
\text { máxima de } \\
\text { um parque }\end{array}$ & $\begin{array}{c}\% \text { da } \\
\text { pontuação } \\
\text { máxima total }\end{array}$ \\
\hline \multirow{5}{*}{ Ambiental } & $\begin{array}{l}\text { Ar } \\
\text { Redução das emissões de: óxidos de enxofre (SOx); óxidos de } \\
\text { nitrogênio (NOx); cinzas; material suspenso particulado; poeira; } \\
\text { compostos orgânicos voláteis não-metânicos; ruído; odores; outros). }\end{array}$ & 9 & $11,1 \%$ \\
\hline & $\begin{array}{l}\text { Terra } \\
\text { Prevenção da poluição pelo descarte de resíduos sólidos no final da vida } \\
\text { útil; produção ou utilização de composto orgânico; produção ou } \\
\text { utilização de nutrientes do solo; uso de tecnologia ecoeficiente de } \\
\text { irrigação; uso de medidas para prevenir a erosão ou salinização do solo; } \\
\text { prática de cultivo mínimo; outras melhorias. }\end{array}$ & 7 & $8,6 \%$ \\
\hline & $\begin{array}{l}\text { Água } \\
\text { Melhoria da gestão ou controle de águas residuais; Economia ou } \\
\text { conservação de água; melhoria da confiabilidade e acessibilidade do } \\
\text { abastecimento de água para a comunidade; garantia à comunidade de } \\
\text { água potável pela purificação da fonte existente ou de fonte limpa; } \\
\text { Melhoria da qualidade da água dos corpos hídricos; outras melhorias. }\end{array}$ & 6 & $7,4 \%$ \\
\hline & $\begin{array}{l}\text { Recursos naturais } \\
\text { Proteção ou melhoria: da gestão dos recursos minerais; dos biomas; da } \\
\text { diversidade da flora e fauna; do manejo das florestas; outras melhorias. }\end{array}$ & 5 & $6,2 \%$ \\
\hline & Total da dimensão ambiental & 27 & $33,3 \%$ \\
\hline Social & $\begin{array}{l}\text { Empregos } \\
\text { Criação de: novos postos de trabalho em longo prazo; novos postos de } \\
\text { trabalho em curto prazo (durante a implantação); novas fontes de } \\
\text { geração de renda; outras oportunidades de emprego. }\end{array}$ & 4 & $4,9 \%$ \\
\hline
\end{tabular}

Revista de Gestão Social e Ambiental - RGSA, São Paulo, v. 12, n. 2, p. 71-89, maio/ago. 2018. 


\begin{tabular}{|c|c|c|c|}
\hline Dimensões & Critérios / Indicadores & $\begin{array}{l}\text { Pontuação } \\
\text { máxima de } \\
\text { um parque }\end{array}$ & $\begin{array}{c}\% \text { da } \\
\text { pontuação } \\
\text { máxima total }\end{array}$ \\
\hline & $\begin{array}{l}\text { Saúde e segurança } \\
\text { Redução ou prevenção: de doenças; de acidentes ou incidentes; redução } \\
\text { do risco: à saúde causado pela poluição dos ambientes internos; de } \\
\text { deslizamentos de terra; de incêndio ou explosão; redução da } \\
\text { criminalidade; melhoria: da segurança alimentar; dos serviços de saúde } \\
\text { oferecidos às comunidades; do saneamento básico e do gerenciamento } \\
\text { de resíduos; outras melhorias. }\end{array}$ & 10 & $12,3 \%$ \\
\hline & $\begin{array}{l}\text { Educação } \\
\text { Fornecimento de cursos de formação relacionados com o trabalho; } \\
\text { aprimoramento da qualidade dos serviços educacionais; difusão de } \\
\text { conhecimentos relacionados ao projeto; outros benefícios. }\end{array}$ & 4 & $4,9 \%$ \\
\hline & $\begin{array}{l}\text { Bem estar } \\
\text { Melhoria das condições de trabalho; contribuição para o } \\
\text { desenvolvimento rural/das comunidades; atenuação da pobreza; } \\
\text { melhoria da distribuição de riqueza ou geração de renda para a } \\
\text { comunidade; aumento das receitas municipais; empoderamento das } \\
\text { mulheres; redução do tráfego; promoção da harmonia e coesão social; } \\
\text { criação de oportunidades, mecanismos ou ferramentas para responder às } \\
\text { necessidades das partes interessadas locais; compartilhamento de forma } \\
\text { equitativa da receita dos créditos de carbono; percepção positiva por } \\
\text { parte dos atores locais sobre a contribuição do projeto para melhoria das } \\
\text { condições de vida; redução da migração na área de influência do } \\
\text { projeto; cuidado com crianças e pessoas em situação vulnerável; } \\
\text { inclusão de grupos vulneráveis em discussões/atividades do projeto; } \\
\text { Outros benefícios. }\end{array}$ & 15 & $18,5 \%$ \\
\hline & Total da dimensão Social & 33 & $40,7 \%$ \\
\hline \multirow{4}{*}{ Econômica } & $\begin{array}{l}\text { Crescimento } \\
\text { Realização de novo investimento econômico como resultado do projeto; } \\
\text { oportunização do início de novas atividades industriais ou comerciais; } \\
\text { criação e manutenção de nova infraestrutura; geração de ativo relevante } \\
\text { para a empresa; aumento da eficiência das atividades produtivas } \\
\text { existentes; redução dos custos de produção ou de serviços; criação de } \\
\text { novas oportunidades de negócios; aumento do turismo local; outros } \\
\text { benefícios. }\end{array}$ & 9 & $11,1 \%$ \\
\hline & $\begin{array}{l}\text { Energia } \\
\text { Melhoria da cobertura/disponibilidade do fornecimento de energia; } \\
\text { melhoria do acesso à energia; aumento da acessibilidade ou } \\
\text { confiabilidade da energia; redução da dependência de fontes externas de } \\
\text { energia; promoção de utilização sustentável da energia; outras } \\
\text { melhorias. }\end{array}$ & 6 & $7,4 \%$ \\
\hline & $\begin{array}{l}\text { Transferência de tecnologia } \\
\text { Introdução, desenvolvimento ou difusão: de tecnologia importada; de } \\
\text { novas tecnologias locais; adaptação de novas tecnologias para as } \\
\text { circunstâncias locais; atividades que constroem know-how para o } \\
\text { desenvolvimento de novas tecnologias; envolvimento das universidades } \\
\text { locais ou centros de investigação para o desenvolvimento, utilização ou } \\
\text { difusão de tecnologia; outros benefícios. }\end{array}$ & 6 & $7,4 \%$ \\
\hline & Total da dimensão econômica & 21 & $25,9 \%$ \\
\hline & Total geral & 81 & $100,0 \%$ \\
\hline
\end{tabular}

Figura 2 - Modelo de análise dos cobenefícios para o desenvolvimento sustentável e pontuação máxima por critério de análise

Fonte: Elaborado pelos autores a partir de Unfccc (2012), Fernández (2014) e Paiva (2015)

Para sistematização, foram utilizadas planilhas em Excel com os dados dos 47 projetos estudados. Os dados quantitativos obtidos acerca dos projetos de MDL passaram por um tratamento estatístico para a elaboração do seu perfil. Já os dados qualitativos referentes aos cobenefícios 
declarados foram tratados utilizando uma escala com três graus de contribuição para cada indicador de cobenefício constante do modelo de análise: '+1' (mais um), '0' (zero) e '-1' (menos um). Então, os projetos deveriam ser pontuados com '+1' (mais um) para cada cobenefício declarado nos documentos analisados como uma contribuição para o desenvolvimento sustentável; com '0' (zero) quando não fosse citada a contribuição; e com '-1' (menos um) se houvesse uma previsão de contribuição negativa do projeto para o dado indicador.

Assim, possibilitou-se a quantificação de informações qualitativas, de forma que um único parque eólico poderia ter uma pontuação máxima hipotética de 81 pontos, correspondentes aos 81 indicadores estabelecidos em um total de 11 critérios distribuídos pelas três dimensões da sustentabilidade. Esta pontuação é hipotética devido à abrangência do modelo de análise, desenvolvido para qualquer tipo de projeto de MDL. Na Figura 2, além do modelo analítico, é apresentada a distribuição dos pontos máximos teóricos de um parque pelos critérios de análise, em quantidade e percentual. Nota-se que a dimensão com maior pontuação máxima é a social, com $40,7 \%$ do total, seguida pela ambiental $(33,4 \%)$ e, por fim, pela econômica $(25,9 \%)$. Isto se deve ao fato de a dimensão social possuir o maior número de indicadores, principalmente em relação aos critérios "Bem-estar" (15 indicadores) e "Saúde e segurança" (10 indicadores). Este peso maior dado à dimensão social no modelo ocorre em razão de estudos realizados anteriormente detectarem uma tendência a menores contribuições dos projetos de MDL para esta dimensão (Fernández et al., 2012; Fernández, 2014; Paiva, 2015; Paiva et al., 2015; Lazaro \& Gremaud, 2017).

\section{APRESENTAÇÃO E DISCUSSÃO DOS RESULTADOS}

\subsection{Perfil dos projetos de MDL de energia eólica do nordeste brasileiro}

Inicialmente, é traçado e discutido o perfil dos 47 parques eólicos cadastrados como MDL no Nordeste Brasileiro, mostrando, principalmente em forma gráfica, suas características predominantes. Quanto à localização, os parques estudados se concentram no estado do Rio Grande do Norte (20 parques, que correspondem a 43\% do total), conforme se vê na Figura 3. Tal achado corrobora os dados do boletim anual de geração eólica 2016, que aponta o Rio Grande do Norte como o maior estado brasileiro gerador de energia proveniente desta fonte (Abeeólica, 2016a).

No tocante à localização específica, esses se encontram instalados em distritos ou pequenos municípios, podendo abranger mais de um, a depender do seu porte. Tanto no Rio Grande do Norte quanto no Ceará, nota-se uma concentração de parques em municípios litorâneos, enquanto na Bahia estes se localizam no interior do Estado, principalmente em regiões mais centrais.

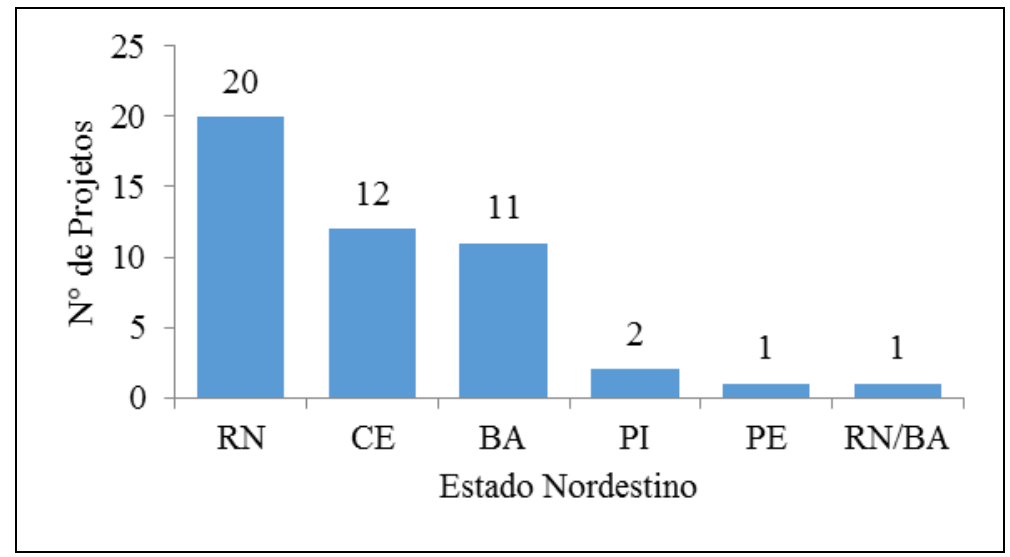

Figura 3 - Localização dos parques eólicos do Nordeste Brasileiro cadastrados como MDL Fonte: Elaborado pelos autores (2017)

Quanto ao histórico destes parques, analisando as datas de submissão inicial dos projetos de MDL à Unfccc, as datas de registro e de início da contagem do $1^{\circ}$ período de crédito de carbono, 
observa-se na Figura 4 uma grande concentração de submissões e registros no ano de 2012. Isto ocorreu devido ao fato de terminar neste ano o primeiro período de compromisso firmado no Protocolo de Kyoto (Brasil, s/d; Andrade \& Costa, 2008). Como consequência, as datas iniciais do $1^{\circ}$ período de crédito de carbono concentraram-se nos anos de 2013 e 2014. Para a grande maioria dos projetos de MDL estudados, este período tem a duração de sete anos e pode haver mais dois períodos de crédito subsequentes. Durante este período, as reduções das emissões de GEE precisam ser monitoradas pelo desenvolvedor do projeto e, após a verificação dessas reduções, por uma Entidade Operacional Designada (EOD) credenciada pelo Conselho Executivo do MDL, os créditos de carbono podem ser emitidos e então comercializados no Mercado Regulado de Carbono (Fernández, 2014; Paiva et al., 2012).

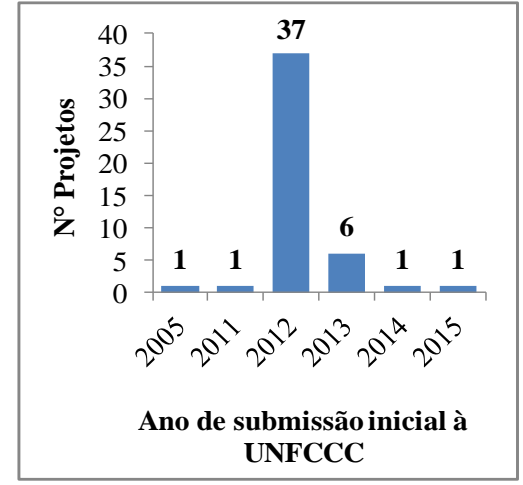

(a)

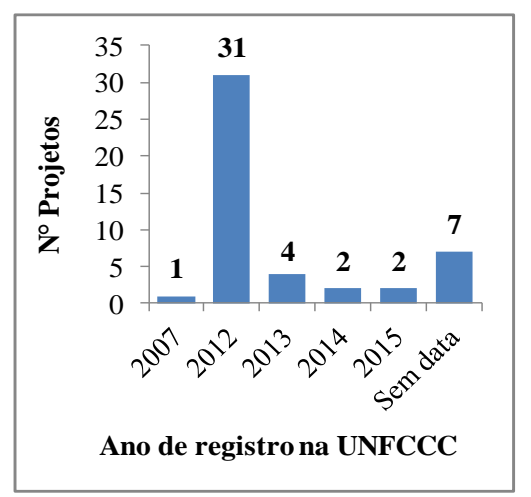

(b)

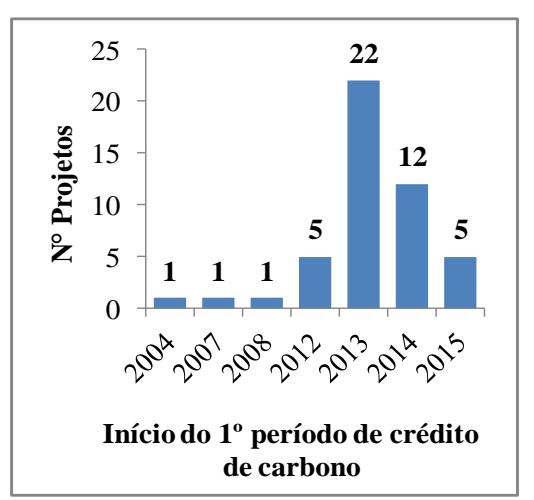

(c)

Figura 4 - Anos de submissão (a), registro (b) e do início do $1^{\circ}$ período de crédito (c) Fonte: Elaborado pelos autores (2017)

No que se refere aos atores-chaves envolvidos no processo, foram mapeados os investidores, os consultores do DCP e os fornecedores dos aerogeradores. Os investidores são os responsáveis pelo desenvolvimento dos projetos de $\mathrm{MDL}$ - frequentemente elaborados mediante a contratação de consultorias especializadas - e pelo posterior gerenciamento dos parques eólicos implantados. Como o principal equipamento desses parques são os aerogeradores, estes correspondem à maior parte do investimento realizado e seus fornecedores são um agente econômico muito relevante.

Analisando a Figura 5, percebe-se que existe no Nordeste certa disseminação dos projetos de MDL de energia eólica entre os atores-chaves. Estes atores-chaves são, em sua maioria, grandes empresas com atuação global. Entre os investidores e consultores, é possível encontrar empresas brasileiras, porém entre os fornecedores de aerogeradores, foram identificadas apenas multinacionais de origem estrangeira, detentoras da tecnologia de geração eólica. Pode-se destacar como principal investidor a Gestamp, empresa de origem espanhola, proponente de sete projetos de MDL; como principais consultorias a CO2 Global Solutions, também de origem espanhola, e a Eqao, de origem brasileira; e, como principais fornecedores de aerogeradores, a Vestas (dinamarquesa) e a Siemens (alemã). 


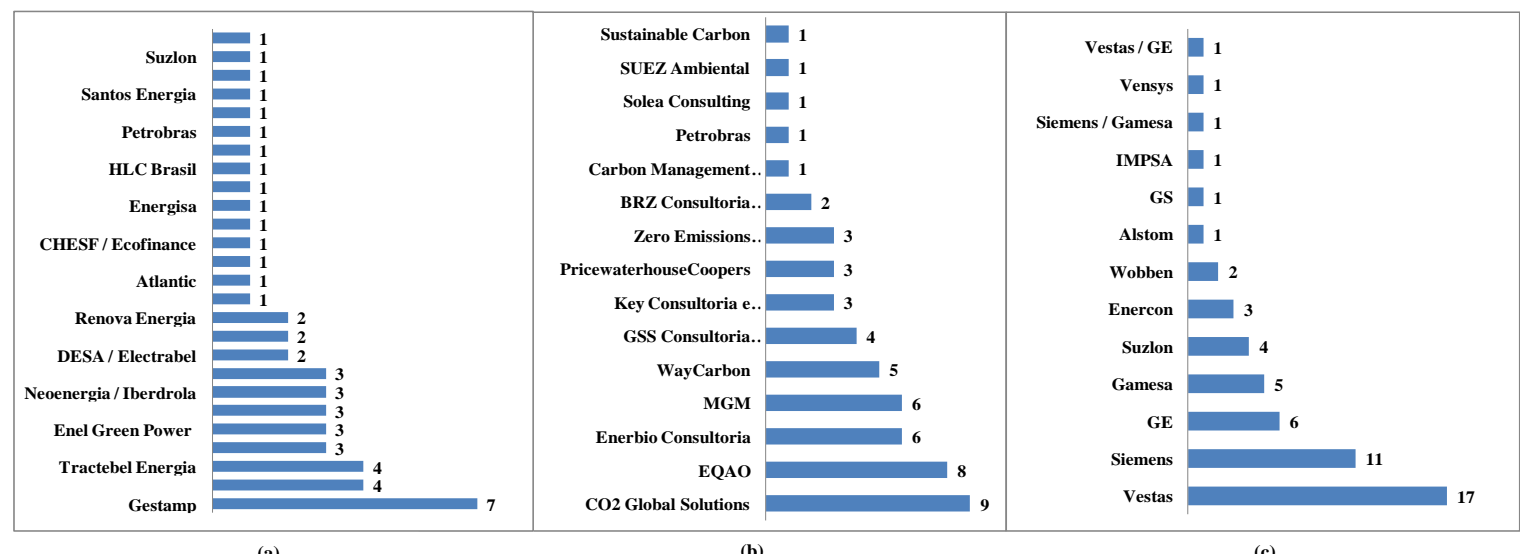

(a)

(c)

Figura 5 - Número de projetos por investidor (a), consultor do DCP (b) e fornecedor dos aerogeradores (c)

Fonte: Elaborado pelos autores (2017)

Por fim, foram levantados os dados quantitativos dos projetos, referentes ao número de aerogeradores, à potência, ao investimento, e à redução anual média estimada das emissões de GEE. Vale destacar que quase todos os projetos adotam a mesma metodologia de cálculo da redução das emissões estabelecida pela Unfccc: a "Metodologia consolidada de grande escala: geração de eletricidade conectada à rede a partir de fontes renováveis" (ACM0002). Os cálculos utilizam como referência um cenário de linha de base, que, no caso da grande maioria dos projetos estudados, foi a manutenção da situação atual, ou seja, na ausência do projeto, a energia - que passaria a ser fornecida à rede por este - seria gerada pelas centrais já em operação, que são majoritariamente hidrelétricas e termelétricas movidas a combustíveis fósseis.

Conforme se vê nos histogramas da Figura 6, os dados quantitativos dos projetos apresentam comportamentos similares, uma vez que possuem correlação positiva, ou seja, quanto menor a quantidade de aerogeradores, menores o investimento, a potência do parque e a redução das emissões e vice-versa.
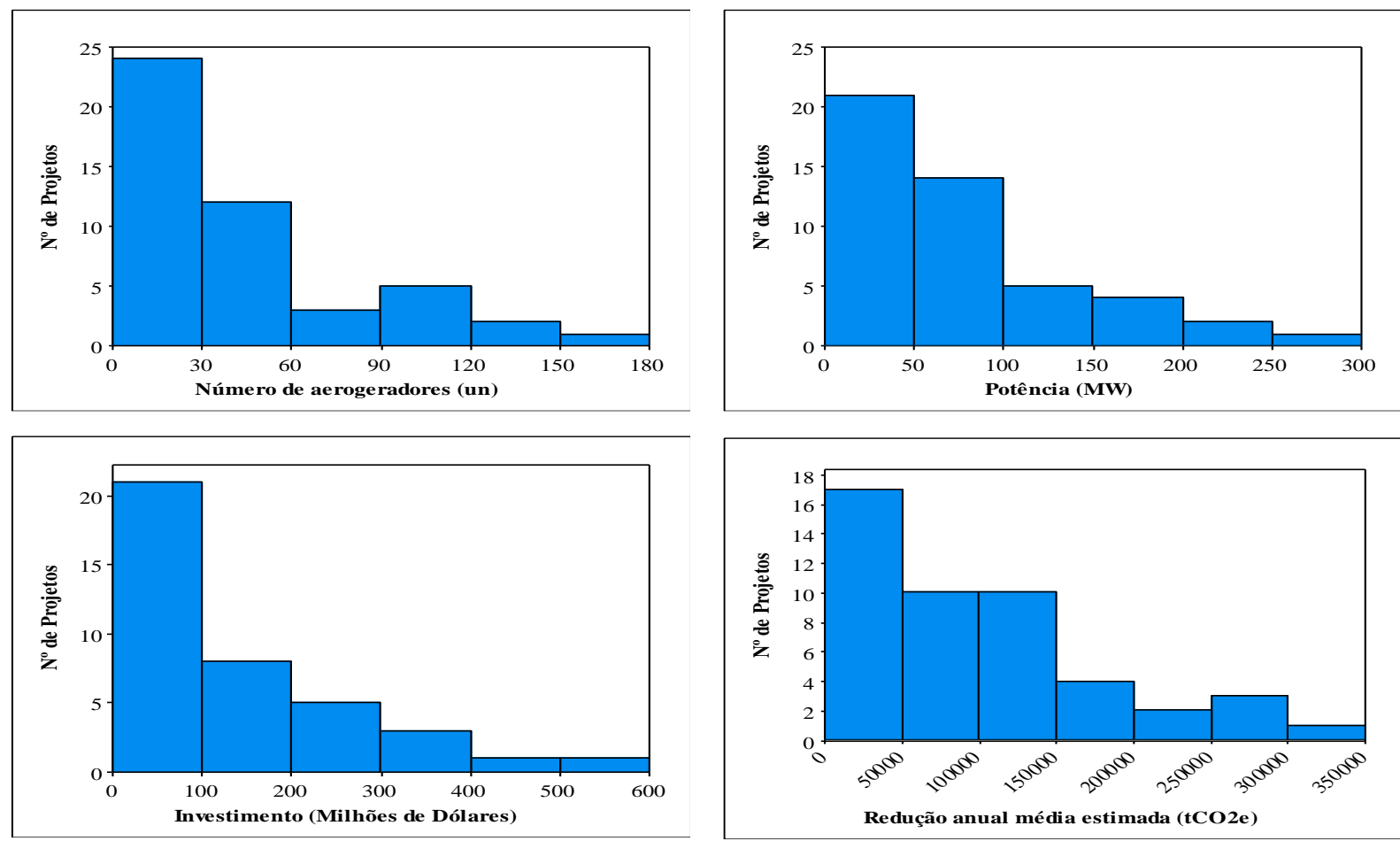

Figura 6 - Histogramas dos projetos de MDL de energia eólica do Nordeste Brasileiro Fonte: Elaborado pelos autores (2017) 
Com base nos gráficos mostrados na Figura 6, pode-se concluir que existe uma grande concentração de projetos de MDL de energia eólica de menor porte. Isto ocorre porque os parques devem possuir individualmente uma potência instalada de, no máximo, $30 \mathrm{MW}$ para que sejam classificados como Sociedades de Propósito Específico (SPE) e assim possam tirar proveito dos benefícios do regime tributário de lucro presumido (Sousa \& Nascimento, 2012).

Assim, dos 47 projetos de MDL pesquisados, 21 (44,7\%) projetaram gerar até $50 \mathrm{MW}$ de capacidade e receber investimentos de até 100 milhões de dólares; $24(51,1 \%)$ previram a operação com menos de 30 aerogeradores; e 17 parques $(36,2 \%)$ estimaram sua redução anual média de GEE em até 50.000 toneladas de $\mathrm{CO}_{2}$ equivalente. Estes achados estão de acordo com os dados da ABEEólica (2016a), a partir dos quais foi possível inferir que a média de potência dos parques eólicos brasileiros em 2016 foi de 25 MW e que a redução de GEE estimada por parque foi de 41.418,60 toneladas de $\mathrm{CO}_{2}$ equivalente.

\subsection{Cobenefícios declarados nos projetos de MDL de energia eólica do Nordeste Brasileiro}

Os cobenefícios declarados nos projetos de MDL de energia eólica do Nordeste Brasileiro identificados na pesquisa documental foram sintetizados na Figura 7. O somatório da pontuação obtida por todos os 47 projetos (409 pontos) foi pequeno, representando apenas 10,7\% quando comparado com a pontuação máxima teórica deles (3807 pontos). Este achado vai ao encontro do que defendem Olsen, Arens \& Mersmann (2017) de que é necessário desenvolver internacionalmente ferramentas que permitam maximizar os cobenefícios dos projetos e ainda evitar impactos negativos.

Apesar do modelo de análise apresentar a maior pontuação máxima teórica na dimensão social, observou-se que as dimensões social e econômica obtiveram a mesma pontuação (172 pontos), equivalente ao percentual de $42,1 \%$, denotando que os proponentes dos projetos de MDL enfatizaram, nos DCP, os cobenefícios econômicos. Este achado corrobora as pesquisas de Bogo (2012), Fernández et al. (2012), Paiva (2015) e Lazaro \& Gremaud (2017).

A dimensão ambiental somou apenas 65 pontos, que representam 15,9\% da pontuação total, o que pode ser visto como um indício de que esta dimensão é percebida como menos relevante pelos proponentes dos projetos. Esse resultado se coaduna com a conclusão de que é necessário promover a geração de maiores cobenefícios ambientais pelos projetos de MDL de energia eólica (Xue et al., 2015). Acredita-se que parte deste baixo desempenho na dimensão ambiental deve-se ao fato de que a maior contribuição das energias renováveis para essa dimensão está na redução das emissões de GEE, não considerada como cobenefício nos projetos de MDL.

\begin{tabular}{|c|l|c|c|}
\hline Dimensões & \multicolumn{1}{|c|}{ Critérios } & $\begin{array}{c}\text { Pontuação dos } \\
\mathbf{4 7} \text { projetos }\end{array}$ & Percentual \\
\hline \multirow{5}{*}{ Ambiental } & Ar & 37 & $9,0 \%$ \\
\cline { 2 - 4 } & Terra & 0 & $0,0 \%$ \\
\cline { 2 - 4 } & Água & 7 & $1,7 \%$ \\
\cline { 2 - 4 } & Recursos naturais & 21 & $5,1 \%$ \\
\cline { 2 - 4 } & Total da dimensão ambiental & $\mathbf{6 5}$ & $\mathbf{1 5 , 9 \%}$ \\
\hline \multirow{5}{*}{ Social } & Empregos & 98 & $24,0 \%$ \\
\cline { 2 - 4 } & Saúde e segurança & 2 & $0,5 \%$ \\
\cline { 2 - 4 } & Educação & 14 & $3,4 \%$ \\
\cline { 2 - 4 } & Bem-estar & 58 & $14,2 \%$ \\
\cline { 2 - 4 } & Total da dimensão social & $\mathbf{1 7 2}$ & $\mathbf{4 2 , 1 \%}$ \\
\hline \multirow{5}{*}{ Econômica } & 67 & $16,4 \%$ \\
\cline { 2 - 4 } & Crescimento & 65 & $15,9 \%$ \\
\cline { 2 - 4 } & Energia & 40 & $9,8 \%$ \\
\cline { 2 - 4 } & Transferência de tecnologia & $\mathbf{1 7 2}$ & $\mathbf{4 2 , 1 \%}$ \\
\cline { 2 - 4 } & Total da dimensão econômica & $\mathbf{4 0 9}$ & $\mathbf{1 0 0 , 0 \%}$ \\
\hline
\end{tabular}

Figura 7 - Cobenefícios dos projetos de MDL de energia eólica do Nordeste

Fonte: Elaborado pelos autores (2017)

Revista de Gestão Social e Ambiental - RGSA, São Paulo, v. 12, n. 2, p. 71-89, maio/ago. 2018. 
Na Figura 8, a seguir, pode-se visualizar melhor os cobenefícios declarados nos projetos, apresentados em termos dos percentuais em cada dimensão, dispostos em ordem decrescente.

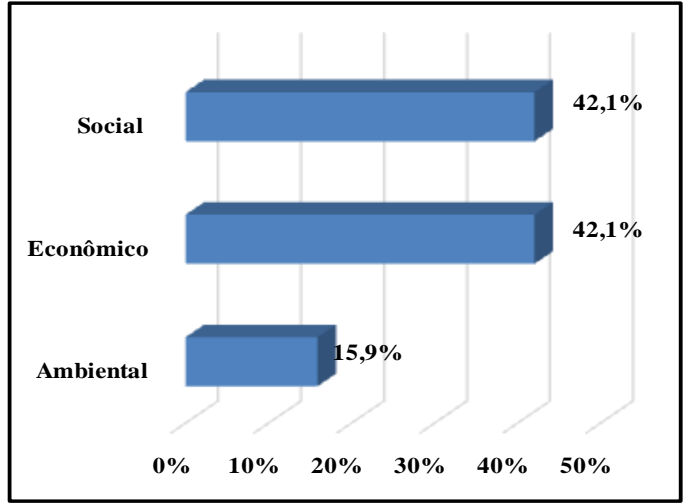

(a) Co-benefícios geral

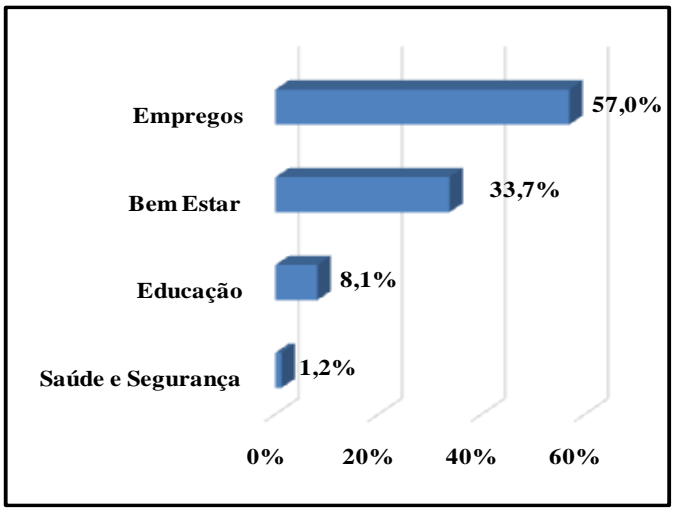

(c) Co-benefícios sociais

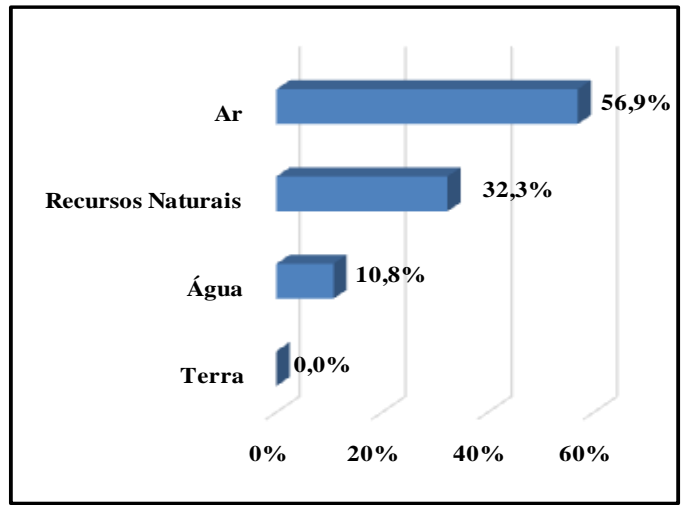

(b) Co-benefícios ambientais

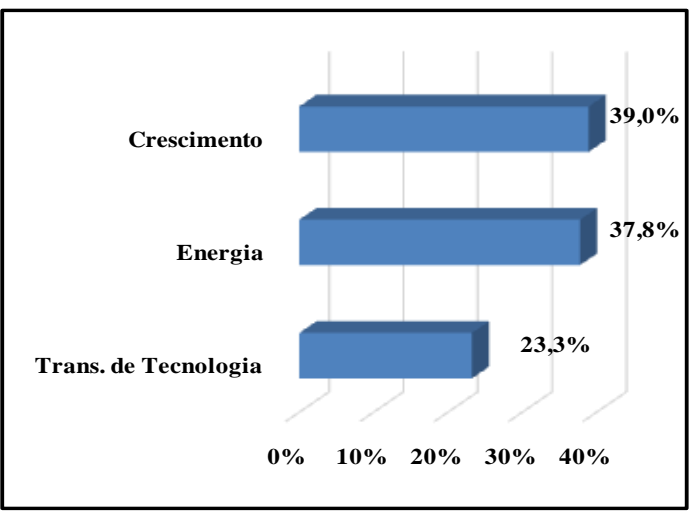

(d) Co-benefícios econômicos

Figura 8 - Cobenefícios dos projetos de MDL de energia eólica do Nordeste por dimensão

Fonte: Elaborado pelos autores (2017)

Com base nessa análise desta figura, fica patente como os cobenefícios ambientais declarados são muito inferiores aos econômicos e sociais. A melhoria da qualidade do ar (56,9\% dos cobenefícios ambientais) e a proteção ou melhoria da gestão dos recursos naturais $(32,3 \%)$ são os critérios que se destacam nesta dimensão. Neste ponto, cumpre destacar que, assim como a redução da emissão de GEE, também os cobenefícios para o desenvolvimento sustentável dos projetos de MDL são definidos tomando como referência um cenário de base que pressupõe a ausência do projeto. No caso da energia eólica no Nordeste Brasileiro, a geração se deu pela utilização de centrais hidrelétricas e termelétricas. Portanto, conforme esperado, apesar da dimensão ambiental ter obtido uma pontuação baixa, o cobenefício ambiental mais citado foi a melhoria da qualidade do ar. Esta melhoria diz respeito à redução de outros poluentes atmosféricos, como $\mathrm{SO}_{2}$, $\mathrm{NO}_{\mathrm{x}}$ e material particulado, que seriam emitidos no caso da geração de energia a partir de termelétricas movidas a combustíveis fósseis, achado semelhante ao encontrado por Xue et al. (2015).

Quanto aos cobenefícios sociais, a geração de novas oportunidades de emprego foi o principal critério declarado ( $57,0 \%$ dos cobenefícios sociais, que equivalem a $42,1 \%$ do total), seguido pela melhoria no bem-estar da população, com 33,7\%. Várias pesquisas têm revelado resultados semelhantes em relação à criação de empregos (Unfccc, 2012; Bogo, 2012; Fernández et al., 2012; Simas e Pacca, 2013; Fernández, 2014; Paiva, 2015; Lazaro \& Gremaud, 2017). Vale ressaltar que a geração de empregos é um indicador de cobenefício que vem sendo incluído, nas pesquisas citadas, alternativamente na dimensão econômica ou na social, a depender do modelo de análise. No grande estudo da Unfccc (2012), que abrangeu todos os projetos existentes no mundo 
até aquele momento, concluiu-se que o cobenefício mais declarado nos DCP foi a dinamização da economia local, incluindo a criação de emprego e redução da pobreza. Nesta pesquisa, por exemplo, nota-se que a geração de empregos foi incluída na dimensão econômica.

Apesar desses achados, faz-se necessário lembrar que os empregos gerados são, principalmente, de curto prazo, durante a construção dos parques eólicos (Simas e Pacca, 2013). Para operação e manutenção dos parques, a quantidade de postos gerados é muito menor, com exigência de mão de obra especializada. Assim, os postos de trabalho passíveis de serem ocupados por pessoas das comunidades do entorno dos parques - localizados em municípios pequenos, caracterizados por uma situação socioeconômica pouco favorável - são frequentemente temporários e ou de baixa qualificação, conforme destacam Silva et al. (2013).

Por fim, os cobenefícios econômicos mais citados neste estudo foram o estímulo à economia regional e a melhoria na disponibilidade ou no acesso à energia, com 39,0\% e 37,8\% do total dos cobenefícios econômicos, respectivamente. O cobenefício de estímulo à economia regional foi apontado também pelos pesquisadores citados anteriormente e, neste caso, se amplifica pelo fato de a instalação desses grandes parques acontecer em pequenas localidades. No tocante à energia, os achados se assemelham aos de Lazaro \& Gremaud (2017), em que 51\% dos DCP estudados declararam contribuir para a segurança energética. A questão da diversificação das fontes energéticas e do desenvolvimento das energias renováveis também são achados desta pesquisa que corroboram os estudos de Zhou, Li \& Huang (2015).

\section{CONSIDERAÇÕES FINAIS}

Retomando o objetivo deste trabalho, sintetiza-se aqui o perfil dos projetos de MDL de energia eólica localizados no Nordeste Brasileiro e seus cobenefícios para o desenvolvimento sustentável declarados nos DCP.

Os projetos estudados localizam-se em distritos ou pequenos municípios, concentrando-se no estado do Rio Grande do Norte, porém são também expressivos na Bahia e no Ceará. Dois terços deles foram submetidos e registrados em 2012, devido ao fato de terminar neste ano o primeiro período de compromisso firmado no Protocolo de Kyoto (2008-2012). Os atores-chaves envolvidos nos projetos são razoavelmente diversificados, destacando-se a Gestamp como principal investidor; a CO2 Global Solutions e a EQAO como consultorias mais atuantes; e Vestas e Siemens, ambas multinacionais de origem europeia, como as principais fornecedoras de aerogeradores. Por fim, quanto ao porte, a maior concentração é de projetos de MDL de energia eólica de pequeno porte.

No tocante aos cobenefícios para o desenvolvimento sustentável, percebeu-se que foi dada pouca ênfase à declaração dos mesmos nos DCP. Boa parte dos projetos deixou de citar cobenefícios evidentes de qualquer projeto de MDL de energia eólica, como, por exemplo, a redução de poluentes atmosféricos não considerados como GEE; a geração de renda para a comunidade (no mínimo, a proveniente do arrendamento de terras para a instalação do parque); e a criação de novas oportunidades de negócios, uma vez que os parques exercem influência considerável na economia local, principalmente por serem localizados em pequenos municípios.

Entre os cobenefícios efetivamente citados, destacam-se os sociais e econômicos, sendo a criação de novos postos de trabalho, tanto de curto como longo prazo, foi o indicador mais declarado nos DCP. A dimensão econômica recebeu um destaque considerável, maior do que esperado, tendo sido os indicadores mais citados o estímulo à economia regional, a promoção do uso sustentável da energia e a introdução e difusão de tecnologia importada. Por fim, a dimensão ambiental foi relegada a um plano secundário. Assim, acredita-se que é necessário estimular a geração de maiores cobenefícios ambientais pelos projetos de MDL de energia eólica do Nordeste Brasileiro.

$\mathrm{Na}$ atual fase da pesquisa, estes achados levantam alguns questionamentos, como, por exemplo: Por que alguns cobenefícios aparentemente estão sendo declarados de forma subestimada e outros de forma superestimada, como parece ser o caso da geração de empregos? 
Considerando os objetivos do governo brasileiro de consolidar uma economia de baixo carbono, reduzir as emissões de GEE e ampliar o uso de fontes diversificadas de energia renovável, percebe-se a importância de utilizar políticas públicas como mecanismos de incentivo a projetos de energia eólica que gerem cobenefícios significativos, de forma a contribuir mais efetivamente para a sustentabilidade da região Nordeste e do Brasil.

Por fim, acredita-se que o MDL - ou o Mecanismo de Mitigação Sustentável (SMM) que o substituirá quando da vigência do Acordo de Paris - pode promover o desenvolvimento sustentável local, desde que inclua a mensuração e verificação dos cobenefícios gerados na prática, de forma similar ao que já acontece no caso da redução das emissões de GEE. Assim, naturalmente, os proponentes dos projetos assumiriam um compromisso maior com a geração de cobenefícios para o desenvolvimento sustentável local.

Quanto às limitações da pesquisa, a principal limitação refere-se à utilização de basicamente uma única fonte de coleta de dados secundários: os documentos de concepção dos projetos. Os cobenefícios declarados nos DCP não necessariamente serão operacionalizados na prática. Assim, visando minimizar esta limitação, tem-se como oportunidade para futuras pesquisas a realização de visitas a campo, de modo a confrontar os DCP com a realidade. Como este trabalho é um work in progress, já estão sendo realizados estudos de caso aplicando o mesmo instrumento de pesquisa em entrevistas em profundidade com gestores dos parques eólicos. Dessa forma, esta análise ex-ante, enfocando os cobenefícios declarados nos DCP, será complementada pela análise ex-post, voltada para os cobenefícios verificados na prática, nos parques eólicos visitados.

\section{REFERÊNCIAS}

Andrade, J. C. S. \& Costa, P. (2008) Mudança climática, protocolo de Kyoto e mercado de créditos de carbono: desafios à governança ambiental global. Organizações \& Sociedade, 15(45), 29-45.

Associação Brasileira de Energia Eólica - ABEEólica (2016a) Boletim anual de geração eólica 2016. Recuperado em: 28 abr.2017, de: 〈http://gesel.ie.ufrj.br/app/webroot/files/IFES/BV/ abeeolica3.pdf> .

Re: Informações sobre usinas eólicas. 2016b. [online] Mensagem pessoal com planilha anexada enviada para a autora. 28 jan 2016.

Bogo, J. (2012) O mecanismo de desenvolvimento limpo no Estado de Santa Catarina e sua contribuição para o desenvolvimento sustentável local. 2012. 424f. Tese (Doutorado em Administração) - Núcleo de PósGraduação em Administração - NPGA, Escola de Administração, Universidade Federal da Bahia, Salvador.

Brasil. Ministério da Ciência e Tecnologia. (s/d). Protocolo de Quioto à Convenção sobre Mudança do Clima: o Brasil e a Convenção-Quadro das Nações Unidas. Brasília: MCT. Apoio do Ministério das Relações Exteriores. Recuperado em 01 nov.2015 de: <http://livroaberto.ibict.br/ handle/1/855>.

Fernández, L. (2014) Evaluación de los co-beneficios sobre el desarrollo sostenible y la reducción de la pobreza de proyectos de mitigación del cambio climático en Brasil. Tese (Doutorado em Engenharia Industrial) - Escuela Técnica Superior de Ingenieros Industriales, Universidad Politécnica de Madrid, Madrid.

Fernández, L., de la Sota, C., Andrade, J. C., Lumbreras, J., Mazorra, J. (2014) Social development benefits of hydroelectricity CDM Projects in Brazil. Intern. Journal of Sustainable Develop. \& World Ecology, 21, 246-258.

Fernández, L., Bogo, J., Lumbreras, J., Andrade, J. C. S. (2012) Exploring co-benefits of clean development mechanism projects: lessons learned from Santa Catarina - Brazil. The International Journal of Climate Change: Impacts and Responses, 3, 121 - 142.

Godoy, G. M. S., Saes, M. S. M. (2015) Cap-and-trade and project-based framework: how do carbon market work for greenhouse emission reduction?. Ambiente \& Sociedade, 18.1, 141-160.

Revista de Gestão Social e Ambiental - RGSA, São Paulo, v. 12, n. 2, p. 71-89, maio/ago. 2018. 
Larragán, J. C. (2016) The Paris agreement, the Kyoto Protocol and the future of the carbon market. International Bar Association. 18 October 2016. Recuperado em: 20 abr. 2017, de: http://www.ibanet.org/Article/ Detail.aspx?ArticleUid=7d6e423c-28c2-4128-bf69-99d0d992f7aa.

Lazaro, L. L. B., Gremaud, A. P. (2017) Contribuição para o desenvolvimento sustentável dos projetos de mecanismo de desenvolvimento limpo na América Latina. $O \& S$ - Salvador, v. 24, n. 80, p. 53-72, Jan./Mar. Recuperado em: 20 abr. 2017, de: https://portalseer.ufba.br/index.php/ revistaoes/article/view/11811/13222.

Lewis, J. I. (2010) The evolving role of carbon finance in promoting renewable energy development in China. Energy Policy, 38, 2875-86.

McDowall, W., Ekins, P., Radošević, S., Zhang, L. (2013) The development of wind power in China, Europe and the USA: how have policies and innovation system activities co-evolved. Technology Analysis \& Strategic Management, 25(2), 163-185.

Ministério da Ciência, Tecnologia e Inovação - MCTI (2014) Status dos projetos do Mecanismo de Desenvolvimento Limpo (MDL) no Brasil. Recuperado em 01 nov. 2015, de:

<http://www.mct.gov.br/index.php/content/view/30317/Status_de_projetos_do_MDL_no_Brasil.html>.

Murata, A., Liang, J., Eto, R., Tokimatsu, K. (2016) Environmental co-benefits of the promotion of renewable power generation in China and India through clean development mechanisms. Renewable Energy, 87, 120-129. Recuperado em: 22 mar. 2017, de:

http://www.sciencedirect.com/science/article/pii/S0960148115303256.

Olsen, K. H., Arens, C. \& Mersmann, F. (2017) Learning from CDM SD tool experience for Article 6.4 of the Paris Agreement. Climate Policy.

Paiva, D. S., Fernández, L., Ventura, A. C., Gomes, G.; Ramos, L. S. (2012) O mercado voluntário de carbono: análise de cobenefícios de projetos brasileiros para o desenvolvimento sustentável. In: Anais do Enanpad - Encontro da Associação Nacional de Pós-graduação e Pesquisa em Administração, Rio de Janeiro, 36.

Paiva, D. S. (2015) Projetos do mercado voluntário de carbono no Brasil: análise dos cobenefícios para o desenvolvimento sustentável. Tese (Doutorado em Administração) - Npga. Escola de Administração, Universidade Federal da Bahia, Salvador.

Paiva, D. S., Fernández, L. G., Ventura, A. C., Alvarez, G., Andrade, J. C. S. (2015) Mercado Voluntário de Carbono: Análise de Co-benefícios de Projetos Brasileiros. RAC, Rio de Janeiro, 19 (1), art. 3, 45-64, Jan./Fev.

Pamplona, N. \& Fraissat, Z. (2017) Energia traz bilhões para Nordeste, mas benefício fica na mão de poucos. Folha de S. Paulo, São Paulo, 25 dez. 2017. Seção Mercado. Recuperado em 27 dez. 2017, de:

<http://tools.folha.com.br/print?site=emcimadahora\&url= http://www1.folha.uol.com.br/ mercado/2017/12/1945898-energia-traz-bilhoes-para-nordeste-mas-beneficio-fica-na-mao-de-poucos.shtml .

Seiffert, M. E. B. (2009) Mercado de carbono e Protocolo de Kyoto:oportunidades de negócio na busca da sustentabilidade. São Paulo: Atlas.

Silva Jr., A. C., Andrade, J. C. S., Telesforo, A. C., Farias, L., Rocha, A., Ramos, E. (2011) Políticas públicas, tecnologias mais limpas e desenvolvimento sustentável: um estudo de projetos de MDL em parques eólicos no Brasil. Revista da UNA (Reuna), 16(2), 103-120.

Silva, N. F., Rosa, L. P., Freitas, M. A. V., Pereira, M. G. (2013) Wind energy in Brazil: from the power sector's expansion crisis model to the favorable environment. Renewable and Sustainable Energy Reviews, 22, 686-697.

Simas, M. \& Pacca, S. (2013) Energia eólica, geração de empregos e desenvolvimento sustentável. Estud. av. [online], 27(77), 99-116.

Souza, A. L. R., Alvarez, G., Andrade, J. C. S. (2013) Mercado regulado de carbono no Brasil: um ensaio sobre divergências contábil e tributária dos créditos de carbono. Organizações \& Sociedade (Online), 20, 675-697. 
Sousa, E. A. C. P. \& Nascimento, R. S. (2012) Avaliação econômica e financeira - Estudo de caso: Projeto Serosa de aproveitamento de energia eólica para geração de energia elétrica. Projeto de graduação (Curso de Engenharia de Produção) - Escola Politécnica, Universidade Federal do Rio de Janeiro, Rio de Janeiro. Recuperado de 20 abr. 2017, de: http://monografias.poli. ufrj.br/monografias/monopoli10004925.pdf.

Unep DTU Partnership (2016) CDM Pipeline. Recuperado em 02 mai. 2016, de: <http://www.cdmpipeline.org/>.

United Nations Framework Conventions on Climate Change - Unfccc (2012) Benefits of the clean development mechanism. Recuperado em: 01 nov. 2015, de:

<https://cdm.unfccc.int/about/dev_ben/ABC_2012.pdf $>$.

United Nations Framework Conventions on Climate Change - Unfccc (2017) CDM Sustainable Development co-Benefits. Recuperado 01 set. 17, de: <http://cdmcobenefits.unfccc.int/ Pages/SDReports.aspx>.

Viola, E. (2005) As complexas negociações internacionais para atenuar as mudanças climáticas. In: Meio Ambiente no Século XXI. Trigueiro, A. (Coord.), Armazém do Ipê Autores Associados, (4 $4^{\mathrm{a}}$ ed.), Campinas/SP.

Watts, D., Albornoz, C., Watson, A. (2015) Clean Development Mechanism (CDM) after the first commitment period: assessment of the world's portfolio and the role of Latin America. Renewable and Sustainable Energy Reviews, 41, 1176-1189.

Xue, B., Ma, Z., Geng, Y., Heck, P., Ren, W., Tobias, M. (2015) A life cycle co-benefits assessment of wind power in China. Renewable and Sustainable Energy Reviews 41, 338-346. Recuperado em: 22 març.2017, de:: http://www.sciencedirect.com/science/article/ pii/S1364032114007321.

Zhao, Z., Li, Z. W., Xia, B. (2014) The impact of the CDM (clean development mechanism) on the cost price of wind power electricity: a China study. Energy, 69, $179-185$. Recuperado em 20 mar. 2017, de: http://www.sciencedirect.com/science/article/pii/S036054421300902X.

Zhou, Y., Li, Y. P., Huang, G. H. (2015) Planning sustainable electric-power system with carbon emission abatement through CDM under uncertainty. Applied Energy. 140, 350-364. Recuperado em: 21 març.2017, de: http://www.sciencedirect.com/science/article/pii/S0306261914012264.

Data da submissão: 09/09/2017

Data de aceite: 07/12/2017 